\section{CONCERNING GIRAFFES.}

THE recent acquisition by the British Museum of specimens from East Central Africa and elsewhere has brought into prominence the question of how best to designate the various forms of giraffe to be met with in different regions of Ethiopian Africa, that is to say, whether they should be regarded as distinct species, local races of a single species, or mere, so to say, accidental variations not worthy of systematic separation. The question has been discussed at length in a paper by the present writer read before the Zoological Society on February 2 , when a number of paintings and photographs of entire specimens, skins, and skulls were exhibited.

Without entering into details, it may be mentioned, as a matter of common knowledge, that the giraffes of northern Africa -including the typical Giraffa camelopardalis of Linnæus-are characterised by the presence in the male of three horns, supplemented in some cases by a rudimentary pair on the occiput, and their white legs. Giraffes of this general type extend at least as far south as the neighbourhood of Lake Baringo and Mount Elgon, that is to say, considerably to the southward of the equator. The accompanying illustration (Fig. 2) exhibits the aforesaid cranial features in the giraffe of the Baringo district.

On the other hand, when the southern districts of the

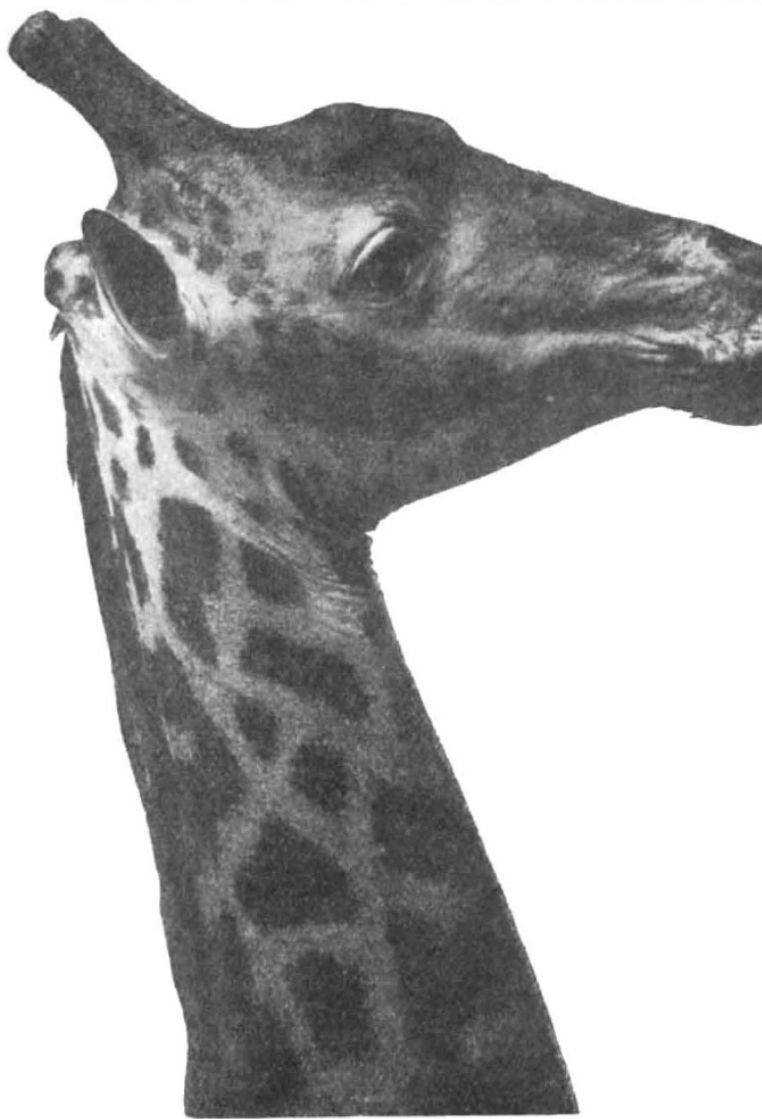

Fig. 1.-.-Head and neck of North Transvaal bull Giraffe, presented to the British Museum by Mr. Rowland Ward, to show Southern type.

continent are reached, we find that the frontal horn of the adult bull giraffes has been reduced to a more or less inconspicuous irregular boss, while the legs have become spotted right down to the hoofs. Giraffes displaying these two characteristics occur as far north as the northern Trans-

NO. 1791 , VOL. 69] vaal, although, so far as can be judged from a single specimen, the form from that region (Fig. I) differs decidedly in its markings and colour from the well-known giraffe of the Cape district, as it also does in certain features of the skull.

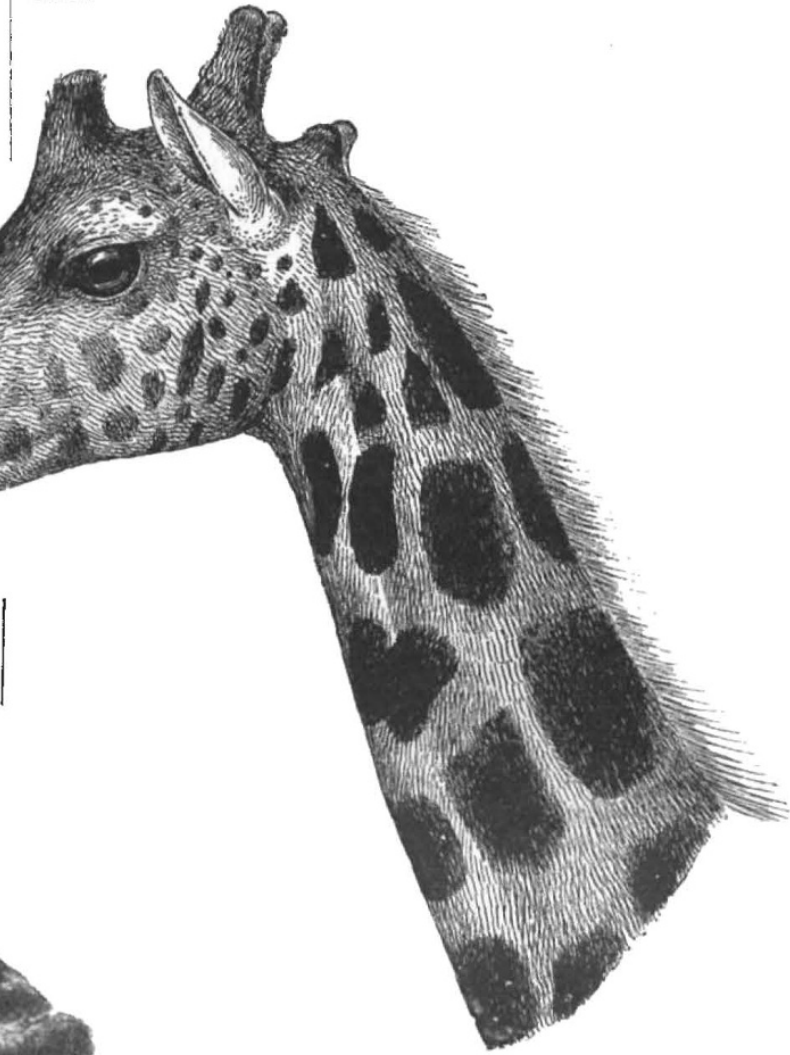

FIG. 2. - Head and neck of old bull of Baringo Giraffe, presented to the British Museum by Sir H. H. Johnston, to show Northern type. (From "Guide to Manmalia in British Museum.")

Apparently, although our information is far from being so complete as is desirable, the nearest approach to a transition between these two extreme types is displayed by the giraffes of the Kilimanjaro district, which have the lower portion of the legs partially spotted, and tend to show less development of the third horn. Not that the known forms in any way form a complete transition between the northern and southern types. On the contrary, they display markings peculiarly their own, and quite unlike those of any of the others.

It has been already stated that there are two distinguishable forms of giraffe belonging to the southern type (and there is a third in Angola). It should be added that equally marked local differences occur in the case of the northern type, the aforesaid Baringo giraffe being strikingly different as regards markings and colour from the Nubian animal, while a giraffe brought by Major Powell-Cotton from the southward of Lado (just north of the equator) appears different from both. Then, again, there is the very strikingly coloured Somali giraffe, which, while agreeing with the northern type in cranial characters, strikes out a line altogether its own in the matter of marking and colour, although in both these respects it merely displays an ultra and bizarre development of the northern type. Nevertheless. it has been regarded as indicating a species apart from the one including all the other forms.

To discuss further the characteristic features of the foregoing and other forms of giraffe until the paper in question has been published would obviously be inadvisable. Sufficient has, however, been stated to afford a general idea of the question at issue, namely, are these various local forms of giraffe constant, and, if so, should they be regarded as species or races? 
Apart from the Somali giraffe, which certainly differs in colour and marking more from all the others than do the latter inter se, the aforesaid tendency to a gradation (with many local side-developments) from the northern threehorned and white-stockinged to the southern two-horned and spot-legged type points to the advisability of regarding the local colour-forms as races rather than species (in the modern sense of both terms). It should be mentioned, however, that at present, at all events, there is no sign of one local form grading into another, although subsequent discoveries may prove this to exist.

Then conies the question, are these local forms constant and invariable (save for individual tendencies towards albinism or melanism)? Dealing solely with available facts, and not admitting hypothesis, the answer to this, so far as our present information goes, is in the affirmative. Of course, additional specimens of each form are desirable, but all the examples of each type at present available poin to the conclusion that such types are constant locally, and it is therefore obvious that it is incumbent on those who dispute this assertion to substantiate their objections by producing specimens showing individual variation in one and the same locality.

As regards the evidence for constancy of local type, it may be mentioned that the herd of Nubian giraffes formerly in the Zoological Society's Gardens, together with the numerous specimens that have of late years been imported into Europe, are amply sufficient to demonstrate the absence of individual variation in this case. The proof of constancy of type is nearly equally strong in the case of the Cape giraffe, despite the fact that as we proceed north a change in the nature of the markings is noticeable. The Baringo and Kilimanjaro giraffes, allowing for marked differences according to age and sex, are also known by a considerable number of specimens, so that there is every probability that their respective types of coloration are fairly constant, and the evidence for such constancy is still more satisfactory in the case of the Somali giraffe. As regards the other named forms, it must be admitted that their right to separation rests on the evidence of single specimens. Still, if constancy of type occurs in the other forms, the presumption is that it also obtains in these.

If, of course, Kilimanjaro giraffes were met with among a Baringo herd, or vice versâ, the case for the racial distinctness of the local forms would be at once demolished, but no evidence of such an admixture of type has ever been recorded. Until this is observed, we are accordingly entitled -or rather compelled-to regard the differences in the colour and markings of giraffes from different localities as indicating local races precisely analogous to those of the bonte-quagga, or Burchell's zebra. The extent of area covered by these local forms, whether some of them may be anything more than individual variation, and whether on the borders of their respective ranges they interbreed with the neighbouring races, or, as is more probable, keep perfectly distinct, are factors in the question still awaiting definite answers.

In conclusion, reference may be made to the extremely important and valuable additions to our knowledge of these animals which have resulted from the specimens collected by Major Powell-Cotton during his recent expedition to East Central Africa. The only pity is that, by reason of the game-preservation laws, he was prevented from bring ing away such a series of examples of the different local forms as would have sufficed to convince even the most sceptical of their respective constancy to a common type.

R. L.

\section{A DIRECTED SYNTHESIS OF AN} ASYMMETRIC COMPOUND.

A LL previous attempts to synthesise an optically active A carbon compound have been based on one principle they have involved the combination of an inactive compound, containing an ethylene linkage or a carbonyl group with an optically active substance to form an ester or glucoside, and the subsequent treatment of this product in such a way as to attach two different groups to a previously ethenoid carbon atom so as to render it asymmetrical. As Prof. Japp and others have pointed out, the two possible isomerides should not necessarily be formed in equal quanti- ties, so that on hydrolysing the new ester or glucoside one of the isomerides would preponderate, and therefore an optically active product should be obtained. Prof. Kipping reduced the bornyl ester of benzoyl formic acid to the bornyl ester of mandelic acid, hoping to obtain an optically active mandelic acid. Prof. Fischer and M. D. Slimmer added hydrogen cyanide to helicin; they then hydrolysed the nitrile and subsequently the glucoside, with the object of preparing active oxymandelic acid.

Prof. Kipping's product proved to be inactive, and it was not conclusively established that that obtained by Fischer was active.

In the last number of the Berichte, Prof. Marckwald, of Berlin, describes the synthesis of active $l$-valerianic acid. Methylethylmalonic acid forms two acid salts, which in the case of the potassium salt are enantiomorphously related<smiles>[R]OC(=O)C(CC)(CC)C(=O)O</smiles><smiles>CCC(C)(C(=O)O)C(=O)O</smiles>

and will possess the same solubility, whereas the two acid salts with an optically active base, such as brucine, will in general have different solubilities. Methylethylmalonic acid. loses carbon dioxide when heated, forming methylethylacetic acid, which contains an asymmetric carbon atom; it is to be supposed that from the acid brucine salts of the malonic acid the free carboxyl group will be preferentially eliminated. Led by these considerations, Prof. Marckwald crystallised the less soluble brucine salt from the mixture of the two in the expectation of obtaining a material in which presumably the one form of the asymmetric compound would preponderate. This salt was heated at $170^{\circ}$. The valerianic acid obtained was optically active to the extent of $-\mathrm{I}^{\circ} \cdot 7$ per Io c.c., which may be taken as an indication of the presence of 10 per cent. of l-valerianic acid.

\section{BAROMETRIC SEESAWS.}

PROF. HOFRATH JULIUS HANN has recently contributed an important paper to the Vienna Academy, an abstract of which is printed in the Akademischen Anzeiger, No. I, of the Kaiserliche Akademie der Wissenschaften in Wien. This paper is entitled "Die Anomalien der Witterung auf Island in dem Leitraume $185 \mathrm{I}$ bis 1900 und deren Beziehungen zu den gleichzeitigen Witterungsanomalien in Nordwest Europa." In this Prof. Hann discusses the relationship between the monthly and yearly means of the temperature, pressure and rainfall of Stykkisholm, in Iceland, for the longest time available, the temperature variations at Greenwich, Brussels and Vienna, the pressure and rainfall variations at Brussels and the pressure variations at Vienna.

The results at which he has arrived are of very great interest, for they show that there is a most intimate connection between Icelandic meteorology and that of northwest Europe. For a full account of these the reader must refer to the abstract itself, but some of the results may be briefly summarised here. In the first place, for the three winter months the pressure variations of north-west and middle Europe are for the most part simultaneously of opposite sign to those at Stykkisholm, while the same reversal occurs to a slight extent with the temperature and rainfall. Again, when the pressure variation for a month in Stykkisholm is negative, the probability for a positive temperature variation in north-east and middle Europe is 0.82 , and vice versa with a probability of o 73. Again contrasting temperature and pressure variations, the following results were obtained :-

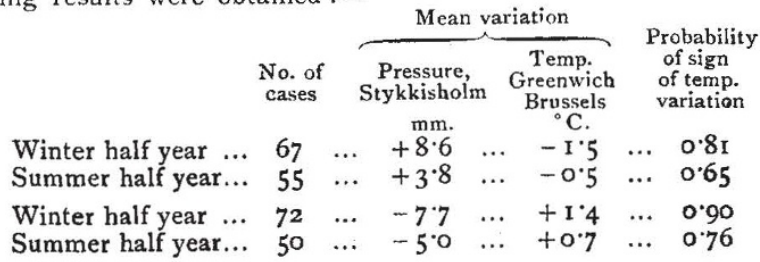

NO. I79I, VOL. 69] 